\title{
The Design and Implementation of Regional Economic Application System Based on Supply Chain Management Model
}

\author{
Yun $\mathrm{Wu}$ \\ \{wuyunjx@163.com\} \\ Department of Economic Management \\ Heilongjiang University of Technology,jixi158100, China
}

\begin{abstract}
The increasingly fierce competition in the retail industry, retailers must establish a new mode to reduce operating costs, reduce inventory and supply chain management idea is make capital flow, information flow, logistics, etc. various kinds of information can be timely and effective in the chain, each node open up, so as to achieve the goal of benefit maximization. Supply chain management as a kind of brand-new management idea, has become the retail companies scramble to adopt management methods, in order to solve the retail industry in the expansion of the existing various problems and contradictions, so as to enhance the core competitiveness of enterprises. The progress of IT Technology (especially Internet technology) provides the possibility for the realization of supply chain management. In the process of supply chain management, the integration of information technology has played a great role in the support of the high efficiency and efficiency of the supply chain. Effective supply chain management information system, which is suitable for its own development, has become the most important task in the management of Chinese retail enterprises. This paper mainly analyzes the structure and function module of the retail supply chain management information system. And through the case analysis of WAL-MART supply chain management information system, the structure of the system to carry out a preliminary proof, in order to form the guiding role of China's retail industry. Finally, it describes the application of electronic data exchange technology, radio frequency identification technology, GIS and GPS and other information technology in the supply chain management.
\end{abstract}

Keywords: Retail industry; supply chain management; supply chain management information system; information technology integration.

\section{Introduction}

Supply chain from an English word of the supply chain, initially only be regarded as a enterprise internal logistics process. It involves mainly the coordination of material purchases, inventory, production and Distribution Department function, the ultimate purpose is to optimize the internal business processes, reducing logistics cost, so as to increase the efficiency of the operation. With the in-depth research and extension of the management and the supply chain management is directs the operation of the supply chain to achieve the optimization and at the least cost, make supply chain procurement from the beginning, to meet 
customer eventually all processes, including flow, logistics, capital flow and information flow are high efficiency operation, get the right product at a reasonable price, timely and accurately sent to the hands of consumers.

Since the 90's of last century, supply chain management has gradually become a hot research topic in the domestic and international business circles and academia. Supply chain management not only in academic research has been focused on the study, but also in practice is being gradually applied to the process of reform and improvement of enterprises. From an international perspective, the early research on supply chain management is mainly focused on the composition of the supply chain, multi-level inventory, supply chain finance and other aspects, mainly to solve the problem of supply chain operation efficiency. In recent years, research on supply chain management is mainly to supply chain management as a strategic management system, and research to the long-term cooperation relationship all the allied enterprises [1], especially concentrated in cooperative manufacturing and the establishment of a strategic partnership, not just supply chain connecting problem, its scope has surpassed that of the supply chain the kind of early to short-term, based on the economic relationship between certain business activities, more emphasis on long-term plan. But the research on supply chain in China has just started. In the past attention of domestic enterprises on the supply chain mainly at the level of a supplier, a manufacturer and is the supply chain for a short, research content mainly limited to supplier selection and positioning, reduce cost, quality control, guarantee the continuity and economic problems of the supply chain, without considering the from suppliers, distributors and retailers to end users, a complete supply chain, but research has not considered the strategic supply chain management problems. Therefore, supply chain management of the entire knowledge system is not perfect, there is yet to be further explored and studied. From the point of view of the theoretical system of knowledge.

\section{The Essence of Supply Chain Management}

The development of supply chain management concept is relatively short. 70s of last century, organizational focus only on business process in a specific functional units, such as manufacturing, marketing or distribution; in the 1980s, the organization began to integrate all aspects of the business links, such as ordering, manufacturing, procurement, thereby greatly improving the productivity. In the 1990s, enterprise organization recognize starting from meeting the demand of quality of service, integrate all the supply relationship, such as retail point of order, distribution center, product assembly, machining parts, raw materials procurement, etc., thus helping to improve the overall competitive advantage.

The so-called supply chain refers to the supply and demand network involved in the process of production and circulation of product raw material suppliers, manufacturers, wholesalers, retailers and consumers, namely, material acquisition, material processing, and the finished products sent to the user in the hands of the process involved in enterprise and the corporate sector consisting of a network. China's current national standard "logistics terms" will be a supply chain is defined as: "supply chain, namely in the process of production and circulation relates to provide products or services to the end users of upstream and downstream enterprises, by the formation of chain structure. Supply chain emphasis is an integrated management ideas and methods, focus on the supply and demand relationship between enterprises, the supply chain of all links in the organic combination of the highest overall efficiency of the supply chain. "Logistics terms" of supply chain management is 
defined as the: "supply chain management, namely the use of computer network technology comprehensive planning in the supply chain of commodity flow, logistics, information flow, capital flow and carries out plan, organization, coordination and control." Supply chain management is refers to the people to know and grasp of supply chain internal rules and mutual relations, utilization and management of planning [2], organization, command, coordination, control and incentive function, involved in all aspects of the process of the production and circulation of logistics, information flow, capital flow, value flow and business flow of reasonable regulation, in order to reach the best combination, play a maximum efficiency, quickly with minimal cost for customers to provide maximum added value. Supply chain management is under the condition of modern science and technology, products are extremely rich conditions developed in the management concept, it relates to all kinds of enterprises and enterprise management, is a cross industry management, and between enterprises as a trading partner, and make joint efforts to maximize the pursuit of common economic interests. Supply chain is the product of socialized mass production, and it is an important form of circulation organization and marketing mode. It has the advantages of high degree of market organization, scale management, organically linked production and consumption, and has a direct guiding role to the production and circulation.

\section{Structure Analysis of Supply Chain Management Information System}

A management information system from the point of view of the user. It always has a goal, with a variety of functions, between the various functions and all contact information, form an organic whole, forming a functional structure. Retail supply chain information system is an integrated system, composed of several subsystems, each subsystem respectively is: headquarters management information system, management information system in distribution center, stores management information system, electronic ordering system, customer relationship management system.

Information system is a computer system, and all kinds of functions are realized by using a lot of system software and application software. Due to the information system, the ultimate goal is to realize the information sharing, so must in support of operation system of the database management system, and the database management system to establish a database to store large amounts of data, realizes the database function definition, establishment and maintenance functions, functions, management functions and data communication function recovery. In the organization of the database, for each subsystem to use public data to establish a shared database, and of those only sub system for their own use, the remaining subsystems without or with less data can build special database.

In addition, under the support of database management system, a large number of application software development, the application software should support different levels of management activities, which is to support the daily business activities, management control and strategic plan. In order to realize the function of the system, the application software can call some public application and support the decision of the database, method, etc [3].

\subsection{Case Analysis of WAL-MART Supply Chain Management Information System}

Wal Mart global procurement center with advanced information technology support to the powerful information management system, from the supplier of choice to the goods, the 
analysis of the data, the assessment and collaboration with suppliers play an important management function.

(1) the supplier's choice of targeted. Before and Wal Mart global procurement center, every supplier need to procurement center database provides a that basic situation of supplier information, procurement center for investigating and analyzing, it said, before selecting suppliers, Wal Mart has received to the rich product information and business information, in before the selection have been considered, which makes selection range is greatly reduced, to avoid the blindness and randomness, also very objective decision will also help to save a lot of manpower, material resources and time cost.

(2) more scientific and effective management of the supplier. Wal Mart global procurement center of a huge database with a change of the state of every piece of goods timely changes to the data, through tracking the data provider and the summary, the procurement center can keep abreast of the supplier's delivery, record sales, after-sales services and customer feedback and other important data, and combining these data to evaluate the suppliers, as an important basis for whether to continue cooperation with suppliers. To cooperate with good suppliers shall be abandoned; for fair cooperation of suppliers. According to the data presented suggestions for improvement, and accordingly in negotiating with present conditions; for selling products, timely delivery, pleasant cooperation suppliers, you can take a more relaxed, more efficient acquisition method, at the same time as a supply chain major suppliers to be long-term cooperation. The close cooperation between the suppliers and the retailers is a lubricant to make the supply chain circulate well, and it is also the important basis of saving the operation cost of the supply chain [4].

(3) to help suppliers to achieve self-management. Wal Mart's data center has with more than 6000 suppliers to establish contact, suppliers can directly into the Wal Mart's sales system and data center through the information management system, direct knowledge to supply their own goods in every shop, every time the sales, and Wal Mart in the warehouse inventory and deployment status, sales forecast, email, and notice of payment and so on, the supplier can grasp the inventory, arranged in a timely manner production, picking delivery, greatly shorten the supply chain logistics and distribution of the time, and help suppliers to control inventory management, realize the self management.

\subsection{Logistics Management Information System}

Wal Mart early use of bar code of goods identification, in 2004, Wal Mart began first in the logistics process using RFID system, when the with RFID tags of the arrival of the goods at the distribution center, the reader will to label all boxes read and check the read information and plans to purchase, shipping records and other detection error and corrected in a timely manner. When the store is put forward to demand, the system will quickly and accurately identify the location of the required goods, and print a store code label, loading and transportation to the store. At the same time, the reader will according to the label will automatically change to state the status of goods delivery. Arrive at the warehouse stores, the installation of automatic scanning to equipped with RFID tag on the goods, in instructions that are stored and shelf location at the same time, the change information of the goods for the storage of state in the warehouse at the entrance of the RFID reader. Because the goods out of storage and distribution management are done automatically by the RFID system, thus speeding up the speed of delivery, improve the picking and distribution process efficiency and accuracy, and reduce the manpower, reduces the cost of distribution. 


\subsection{Application of Information Technology in Supply Chain Management}

Introduction of electronic data interchange (EDI) in the chain of retail industry to improve the operation process, must have the active participation of relevant business executives, it is possible to get success. For example: the use of electronic data interchange (EDI) before ordering messages, retailers may be a fax to the supplier ordering, acceptance department in the purchase acceptance, the need to produce the order as the supplier inspection credentials.

After the use of EDI order message, the supplier will not order a single, the acceptance department should be how to check and accept? If retailers and suppliers are introducing electronic data exchange (EDI) message delivery, the supplier may prior to shipping to notify the shipment of goods and quantity, and retailers should be using learned in advance of the shipment data, prior notice inspection departments to speed up the approval. In short, we must have related business department personnel to participate in, together to develop new processes in conjunction with personnel information, and personnel information to modify the information system, in order to make electronic data exchange (EDI) play a maximum effect, to improve the operation process. Due to the need to integrate different sectors of the job, therefore, the higher the level of business executives involved, the more extensive application level [5].

With the progress of the development of the Internet and communication technology, cross platform, component-based GIS (Geographic Information System) and GPS (Global Positioning System) technology is gradually mature, based on GIS / GPS application will construct a competitive and transparent logistics enterprises. GIS application in logistics analysis, mainly refers to the use of GIS powerful geographic data to improve the logistics analysis technology. The application of GPS in the logistics field can monitor the position of the moving target in real time, and send out the real-time dispatching order to the moving target according to the road traffic situation. And the effective integration of GIS, GPS and wireless communication technology, again supported by a vehicle routing model, the shortest path model, logistics network model, distribution set model and facility location model etc. to establish a powerful logistics information system, logistics becomes real time and the cost of the optimal.

\section{Conclusion}

The geographic information system (GIS), the satellite positioning system (GPS), wireless communication (WAP) and the Internet technology (Web) integration, applied to the logistics and supply chain management. The field of information technology, the country is not fully mature. However, it is believed that with the progress of people's attention and technology, GIS, GPS, WAP and web technology will combine together, common to depict the transparent logistics enterprises, reduce logistics black hole, enhance the competitiveness of domestic logistics enterprises, logistics market will soon open a firm foothold.

\section{References}

[1] Lu Y, Lin J, Wang B. Research on Coordination Mechanism of Mobile Service Supply Chain. Proceedings of the 4th International Conference on Networking and Mobile Computing. (2013) 
[2] Pasternack BA. Using revenue sharing to achieve channel co-ordination for a newsboy type inventory model. Supply ChainManagement: Models, Applications and Research. (2015)

[3] Simon Veronneau, Jacques Roy et al. RFID benefits, costs, and possibilities: The economical analysis of RFID deployment in a cruise corporation global service supply chain. International Journal of Production Economics. (2009)

[4] Erhun F, Keskinocak P, Tayur S. Spot markets for capacity and supply chain coordination. (2012)

[5] Lisa M. Ellram, Wendy L. Tate, Corey Billington. Understanding and Managing the Services Supply Chain. The Journal of Supply Chain Management(2014) 